\title{
Vaginal progesterone in risk reduction of preterm birth in women with short cervix in the midtrimester of pregnancy
}

This article was published in the following Dove Press journal:

International Journal of Women's Health

13 September 2012

Number of times this article has been viewed

\section{Meena Khandelwal \\ Department of Obstetrics and Gynecology, Cooper University Hospital, Camden, NJ, USA}

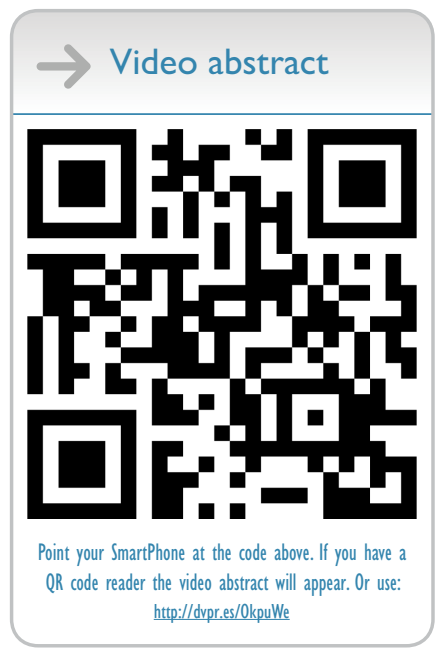

Correspondence: Meena Khandelwal Department of Obstetrics and Gynecology, Cooper University Hospital, 3 Cooper Plaza, 623 Dorrance, Camden, NJ 08103, USA Email khandelwal-meena@cooperhealth. edu

\begin{abstract}
Preterm birth is a major health problem for the neonate, family, country, and society in general. Despite many risk factors being identified for women destined to deliver preterm, short cervical length detected on transvaginal ultrasound is the most plausible, practical and sensitive risk factor for prediction of spontaneous preterm birth. The definition of short cervix has varied in various studies, but most commonly accepted is $\leq 2.5 \mathrm{~cm}$ in the midtrimester of pregnancy, though risk of spontaneous preterm birth (sPTB) increases as the cervical length decreases. Vaginal progesterone, a naturally occurring steroid hormone, is the most bioavailable form of progesterone for uterine and cervical effects with the fewest side effects. Multiple prospective studies have consistently shown its benefits in decreasing SPTB rate in women with asymptomatic midtrimester short cervix. The safety for mother and fetus, and tolerability of vaginal progesterone, particularly the gel form, is also well established. Vaginal progesterone is a minimally invasive intervention that is not painful and is very safe, with reasonable cost where the benefits (even if argued to be small) clearly outweigh the risks. Thus there should be little hesitation for implementation of universal transvaginal cervical length screening and preventive vaginal progesterone treatment for women with short cervix.
\end{abstract}

Keywords: preterm birth, progesterone, short cervix

\section{Overview}

The incidence of preterm birth in United States in 2010 was $11.99 \%$ with $3.5 \%$ born $<34$ weeks' gestation. ${ }^{1}$ This seemingly small group of neonates account for more than $75 \%$ of all neonatal deaths and $35.4 \%$ of all infant deaths. ${ }^{2}$ Of the premature survivors, a quarter have substantial neurological morbidity persisting into adulthood with associated increased emotional, physical, and monetary costs to families and society. ${ }^{3}$ The advancements in technology and health care have resulted in improved survival of preterm infants with resultant increase in absolute numbers of cerebral palsy cases and adolescents with cognitive deficits, academic underachieving, grade failures, and increased need for remedial assistance, as well as increase in mental disorders with associated societal consequences. ${ }^{4}$ Two-thirds of preterm births in the United States are spontaneous (sPTB) and account for half of infant hospitalization costs and a quarter of pediatric costs. ${ }^{5}$ In 2005 , over $\$ 26.2$ billion was spent in the United States on prematurity-related medical problems. ${ }^{6}$ It would make sense that decrease in incidence of prematurity would benefit the mother, the child, the family, and society in general with decreased morbidity, mortality, and societal long-term burden as well as cost savings. As an example, CIGNA HealthCare reported a $\$ 6000$ per pregnancy cost savings with good maternity care resulting in slight decrease in prematurity. ${ }^{7}$ 


\section{Short cervical length}

The first step in prevention of preterm births is adequate identification of at-risk cases (Table 1). For tertiary prevention, onset of uterine contractions with cervical change or rupture of membranes makes it easy to identify patients in preterm labor. Tertiary prevention has proven to be more useful in improving neonatal morbidity with administration of corticosteroids and antibiotics, without much success in actually decreasing the number of preterm births. Therefore focus has shifted towards primary and secondary prevention and led us to identify multiple risk factors for preterm births (Table 2). However, the sensitivity as well as the positive predictive value of any one of these factors or even a combination is poor. Two of the most important predictors of preterm delivery are prior obstetrical history and cervical effacement measured as shortened cervical length (sCL) by ultrasound. Logistic regression analysis has revealed cervical length (CL) to be the single independent contributor to early sPTB ( $\leq 32$ weeks) when neonatal morbidity and mortality is highest. ${ }^{8}$ This also is the most plausible tool for risk assessment since cervical ripening is also the final detectable pathway prior to onset of term labor. Short cervix has been shown in many prospective trials across different populations (US, ${ }^{9,10}$ British, ${ }^{8}$ Finnish $^{11}$ ) to predict sPTB.

Short cervix can be diagnosed by manual digital exam, by Cervilenz (CerviLenz, Chagrin Falls, OH), transabdominal (TAS) or transvaginal ultrasound (TVS). Manual digital exam is subjective, with high failure rate (inability to assess CL) particularly in asymptomatic women with closed cervix, and differences amongst examiners making standardization of findings difficult. ${ }^{9}$ Cervilenz measures the cervico-portio length and in a single prospective trial of 189 patients, correlated with TVS for diagnosing CL $<3 \mathrm{~cm}$ with a sensitivity of $88 \%$ and specificity of $92 \% .{ }^{12}$ Its role so far appears to be in weeding out women with normal CL, requires TVS for confirming a $\mathrm{SCL}$, and requires further investigation to establish role in clinical practice. Ultrasound allows

Table I Levels of prevention

\begin{tabular}{|c|c|c|}
\hline $\begin{array}{l}\text { Level } \\
\text { of prevention }\end{array}$ & $\begin{array}{l}\text { Stage } \\
\text { of disease }\end{array}$ & Goal of therapy ${ }^{64}$ \\
\hline Primary & Pre-disease & $\begin{array}{l}\text { Health promotion (reduce incidence of } \\
\text { the disorder or number of new cases) }\end{array}$ \\
\hline Secondary & $\begin{array}{l}\text { Latent } \\
\text { disease }\end{array}$ & $\begin{array}{l}\text { Early identification and effective } \\
\text { treatment (lower disease prevalence) }\end{array}$ \\
\hline Tertiary & $\begin{array}{l}\text { Symptomatic } \\
\text { disease }\end{array}$ & $\begin{array}{l}\text { Disease limitation for early } \\
\text { symptomatic disease; Rehabilitation } \\
\text { for late disease (reducing severity of } \\
\text { impairment associated with disease) }\end{array}$ \\
\hline
\end{tabular}

objective evaluation of CL, but TVS is favored overTAS. TAS findings result in greater scatter, higher failure rates $(6.7 \%$ compared to $<1 \%$ with TVS),${ }^{13}$ and longer cervix estimation from full maternal bladder and resultant higher false-negative rates. ${ }^{14}$ TVS is an easy skill to learn for sonographers with reported inter- and intraobserver variability of $<5 \%$ (or 2-4 mm). ${ }^{11,15}$ TVS is highly reproducible, safe, and minimally invasive with good acceptability by women. ${ }^{15,16} \mathrm{CL}$ screening by TVS meets the six criteria of a 'good screening tool': validity, reliability, yield, cost, acceptance, and follow-up services. ${ }^{17}$ Despite the low sensitivity, the high negative predictive value $(>97 \%)$ across all trials,${ }^{18}$ makes CL by TVS a useful screening tool for low-risk pregnant women.

A sCL is a good screening predictor as it heralds onset of preterm delivery weeks prior, to allow for intervention to prevent it. ${ }^{14}$ In addition, sCL can be diagnosed reliably and easily by ultrasound which can be performed at the time of an already scheduled visit for fetal anatomic survey. The infrastructure and equipment for TVS already exist in most centers performing fetal ultrasounds though may not be in certain geographic areas.

Many have advocated universal TVS CL screening in all singleton pregnancies. ${ }^{19-21}$ However, the USA Society of Maternal-Fetal Medicine (SMFM) clinical guideline states, "CL screening in singleton gestations without prior SPTB cannot yet be mandated universally," despite acknowledging it fulfills criteria for an effective screening test. ${ }^{22}$ Yet, the guideline recommends TVS CL measurements every 2 weeks in singletons with prior SPTB and provides management decisions for those who choose universal screening in all singleton gestations. This suggests SMFM is encouraging universal screening without mandating it. Resources for TVS when needed for a certain population (women with prior SPTB), as recommended by SMFM, then could also be utilized for other populations. Uncertainty of outcome of screening in actual practice compared to in controlled trials due to population differences, logistical differences in screening protocols, use of therapy beyond the scope of clinical trials or unintended adverse consequences of screening like more TVS or overuse of invasive procedures like cervical cerclage are cited as reasons against universal screening. However, these consequences are inherent in introduction of any proven test or therapy and should be a reason for formulation of strict guidelines and an effective quality assurance program, but not for not requiring the performance of a cost-effective beneficial screening test. ${ }^{23,24}$

The definition of ' $\mathrm{SCL}$ ' is open for debate. There is no cut-off CL when the risk for $\mathrm{SPTB}$ is increased; instead it is a 
Table 2 Clinically identifiable risk factors for spontaneous preterm birth

\begin{tabular}{|c|c|c|c|c|}
\hline & Sensitivity (\%) & PPV (\%) & $\begin{array}{l}\text { False positive } \\
\text { rate }(\%)\end{array}$ & $\begin{array}{l}\text { Relative risk or } \\
\text { odds ratio }\end{array}$ \\
\hline Short cervix & $35-40$ & & & \\
\hline$(<35 \text { weeks })^{8,10,11}$ & 34 & & 5 & \\
\hline$(<32 \text { weeks })^{52}$ & $48(55)$ & & $5(10)$ & \\
\hline Short cervix + vaginal bleeding & & & & $4.6(2.7-8.0)^{65}$ \\
\hline Prior sPTB & & & & $2.0(1.6-2.5)^{66}$ \\
\hline Fetal loss $<16$ weeks & & & & $1.4^{8}$ \\
\hline Fetal loss 16-24 weeks & & & & $1.7^{79}$ \\
\hline sPTB 24-32 weeks & & & & $5.49^{8}$ \\
\hline Short cervix + vaginal bleeding + Prior sPTB & & & & $4.84(1.89-12.4)^{65}$ \\
\hline Risk scoring system $\left(<37\right.$ weeks) ${ }^{67}$ & 38 & & 17 & \\
\hline Multiparous; Nulliparous ${ }^{66}$ & $24.2 ; 18.2$ & $28.6 ; 33.3$ & & \\
\hline Maternal factors $(\mathrm{Age}+\mathrm{Ob} \mathrm{Hx})(<32 \text { weeks })^{52}$ & $29(38)$ & & $5(10)$ & \\
\hline \multicolumn{4}{|l|}{$(<32 \text { weeks })^{52}$} & \\
\hline $\mathrm{FFN}+(<34 \text { weeks })^{68}$ & 61 (33-89) & $9-46$ & & \\
\hline Vaginal bleeding & & & & $1.3(1.1-1.6)^{69}$ \\
\hline \multirow[t]{2}{*}{ (Ist or 2 nd trimester) } & & & & $1.58(1.27-1.96)^{65}$ \\
\hline & & & & $1.6(I .1-2.3)^{66}$ \\
\hline Bacterial vaginosis & & $6-49$ & & I.5-3-fold ${ }^{70}$ \\
\hline Smoking & & & & $1.48^{8}$ \\
\hline Illicit drug use/heavy alcohol use & & & & $1.0^{8}$ \\
\hline Maternal age $<20$ years & & & & $1.42^{8}$ \\
\hline$>35$ years & & & & I.I \\
\hline \multirow[t]{2}{*}{ Ethnicity - Black } & & & & $1.89(1.1-3.27)^{66}$ \\
\hline & & & & $1.66^{8}$ \\
\hline Prior cervical surgery & & & & $1.0^{8}$ \\
\hline Body mass index $<19.8$ & & & & $2.3(1.37-3.92)^{66}$ \\
\hline$>32.2 \pm 2.2 \mathrm{~kg} / \mathrm{m}^{2}(<34$ weeks $)$ & & & & $2.23(1.19-4.18)^{71}$ \\
\hline Clinical depression & & & & $<2$-fold ${ }^{70}$ \\
\hline Socioeconomic status & & & & $2.0(1.19-3.44)^{66}$ \\
\hline Single marital status & & & & $1.4-1.8^{66}$ \\
\hline Long work hours/hard physical labor; stress & & & & $<2$-fold ${ }^{70}$ \\
\hline Interpregnancy interval $<6$ months & & & & $2.2^{72}$ \\
\hline Multiple gestation & $(60)^{70}$ & & & \\
\hline Polyhydramnios/oligohydramnios & & & & $1.8(1.03-3.15)^{73}$ \\
\hline Maternal medical and surgical disorders & & & & $0.7-1.34^{66}$ \\
\hline Uterine anomalies & & & & $5.9(4.3-8.1)^{74}$ \\
\hline Intrauterine; vaginal or maternal systemic infections & & & & Twofold ${ }^{70}$ \\
\hline Periodontal disease & & & & $2.83(1.95-4.1)^{75}$ \\
\hline No risk factors $(>50 \% \text { of all PTBs })^{29}$ & & & & \\
\hline
\end{tabular}

Abbreviations: FFN, fetal fibronectin; Ob $\mathrm{Hx}$, obstetrical history; sPTB, spontaneous preterm births.

continuous variable. The risk of sPTB $\leq 32$ weeks is $0.2 \%$ at CL of $60 \mathrm{~mm}$ at $20-24$ weeks gestation, $0.8 \%$ at $30 \mathrm{~mm}, 1.1 \%$ at $25 \mathrm{~mm}, 1.5 \%$ at $20 \mathrm{~mm}, 4 \%$ at $15 \mathrm{~mm}, 15 \%$ at $10 \mathrm{~mm}$, and $78 \%$ at $5 \mathrm{~mm} .{ }^{8}$ Not only does the risk of sPTB increase as the CL decreases, ${ }^{10}$ there is a linear relationship between length of cervix and gestational age of prior $\mathrm{sPTB} .{ }^{25}$ In addition, the risk of sPTB for a particular CL varies depending on the gestational age it was measured. For example, a CL of $<25 \mathrm{~mm}$ at 20 weeks has a $40 \%$ chance of sPTB $<35$ weeks compared to $70 \%$ if detected at 16 weeks. ${ }^{26}$ Other important factors affecting the predictability of CL include number of fetuses, patient symptoms, and prior history of sPTB. Therefore, for clinical practice, the 'cut-off' CL at which to institute therapy will depend on the balance of detection rate and false positivity considered acceptable and most costeffective. Current studies showing efficacy of therapies (vaginal progesterone or cervical cerclage) in women with 'short cervix' have all been in singleton gestations, asymptomatic women, and CL measured in midtrimester (Table 3) in women with and without prior sPTB. ${ }^{27-31} \mathrm{CL}$ 'cut-off' used in 
Table 3 Frequency of women with short cervix

\begin{tabular}{|c|c|c|c|c|c|c|c|c|c|c|c|}
\hline & \multirow[t]{2}{*}{$\begin{array}{l}\text { GA in weeks } \\
\text { at screening }\end{array}$} & \multicolumn{5}{|c|}{ Cervical length $(\mathrm{mm})$} & \multicolumn{3}{|c|}{$\begin{array}{l}\text { Percentiles } \\
(\mathrm{mm})\end{array}$} & \multirow[t]{2}{*}{$\begin{array}{l}\text { Mean/median } \\
\text { CL }(\mathrm{mm})\end{array}$} & \multirow[t]{2}{*}{ Funne } \\
\hline & & $\leq 15$ & $\leq \mathbf{2 0}$ & $\leq \mathbf{2 5}$ & $\leq \mathbf{3 0}$ & $10-20$ & 1 & 5 & 10 & & \\
\hline Fonseca $^{28}$ & $14-24$ & $1.7 \%$ & & $8.3 \%$ & & & & & & 34 & \\
\hline Heath $^{15}$ & $22-24$ & $1.6 \%$ & $3.4 \%$ & $8.1 \%$ & $18.6 \%$ & & 11 & 23 & & 38 & $8 \%$ \\
\hline Hassan $*, 76$ & $14-24$ & $0.6 \%$ & $0.9 \%$ & $1.7 \%$ & $9.1 \%$ & & & & & $37.5 \pm 6.6$ & \\
\hline To**,52 & $22-24$ & $0.9 \%$ & & & & & & & & 36 & \\
\hline $\operatorname{lams} s^{10}$ & $22-24$ & & $3.0 \%$ & $7.8 \%$ & $23.7 \%$ & & 13 & 22 & 26 & $35.2 \pm 8.3$ & $6.3 \%$ \\
\hline Moroz ${ }^{77}$ & $21-28$ & & & $7.27 \%$ & & & & & 25 & & \\
\hline Hassan ${ }^{29}$ & $19-24$ & & & & & $2.3 \%$ & & & & & \\
\hline Grobman $^{78}$ & $16-22$ & & & & $<30=10.3$ & & & & $<30$ & & \\
\hline
\end{tabular}

Notes: *All were screened by transabdominal ultrasound, followed by TVS only if $\mathrm{CL}<30 \mathrm{~mm}$. In all other studies primary transvaginal screening was performed, suggesting greater detection with TVS; **low-risk population with sPTB $\leq 32$ weeks of $0.6 \%$ (compared to $1.5 \%$ in the Heath cohort $\mathrm{cos}^{15}$ ).

Abbreviations: CL, cervical length; sPTB, spontaneous preterm birth; TVS, transvaginal ultrasound.

different studies has varied between $\leq 15-25 \mathrm{~mm}$. Based on current data, measurement of TVS CL is most appropriate between 19-<24 weeks and women with cervical length of 5-25 mm, with or without prior sPTB, would most benefit from vaginal progesterone; ${ }^{20,30}$ while women with prior sPTB and $\mathrm{CL} \leq 15 \mathrm{~mm}$ would most benefit from cervical cerclage. $^{31}$

\section{Vaginal progesterone Pharmacology, mode of action, pharmacokinetics}

Progesterone is a naturally occurring steroid hormone produced by the adrenals, gonads, nervous system, and placenta in pregnancy. It is a derivative of cholesterol. Cholesterol is converted into pregnenolone by enzyme cytochrome $\mathrm{P} 450$, and pregnenolone is converted to progesterone by $3 \beta$-hydroxy-steroid dehydrogenase $/ \Delta 5, \Delta 4$ isomerase in the smooth endoplasmic reticulum (Figure 1). ${ }^{32}$ Progesterone exerts its modulatory effects on target organs via intracellular receptor isoforms $\mathrm{A}(94 \mathrm{kDa})$ and $\mathrm{B}(116 \mathrm{kDa}) .{ }^{33}$ The receptors are expressed by a single gene on chromosome 11q22-q23 but have separate translational start sites and promoters. Progesterone actions via membrane-based nongenomic receptors have also been illustrated. ${ }^{34}$ In therapeutics, progesterone is available in its natural form or synthetic form. Even though both forms are used for similar purposes, they are not chemically identical and their effect on target organs may not be similar. ${ }^{32,33}$

The natural progesterone is chemically identical to the ovarian progesterone and synthesized from Mexican yams or soybean extracts or animal sources. Its micronization decreases particle size, increases surface area, and thus improves absorption. This results in exponential rise in bioavailability with decreased metabolic and vascular side effects. ${ }^{35}$
The vaginal route further adds advantages to this form by rapid absorption and avoiding the first-pass hepatic metabolism, resulting in sustained plasma concentrations, and high bioavailability especially locally in the most desired target organ, the uterus. This has been termed as the 'first uterine pass effect' as progestational effects on the endometrium are seen despite low plasma levels suggesting direct transit of vaginal progesterone into the uterus. ${ }^{36,37}$ In addition to the above advantages, vaginal route possibly is the preferred mode of administration as the pain associated with oil-based intramuscular (IM) injections, bad taste associated with intranasal route, poor absorption and higher doses with oral route, conflicting evidence and variable effects with transdermal route, and inconvenience with the intravenous or rectal routes is avoided.

Vaginal progesterone is available in the form of gel, suppository, or pessary. Natural and micronized progesterone constitutes all the vaginal forms. Vaginal gel (Crinone/ Prochieve; Watson Pharmaceuticals, Morristown, NJ) is the sustained release form with $90 \mathrm{mg}$ progesterone in $1.125 \mathrm{~g}$ of gel with a $2 \%$ polycarbophil base. The capsule approved for oral use is used as vaginal suppository: $100 \mathrm{mg}$ capsule in peanut oil (Utrogestan; Ferring Pharmaceuticals, West Drayton, UK and Prometrium; Abbott Laboratories, Abbott Park, IL). Compounded 100 or $200 \mathrm{mg}$ suppositories in petroleum jelly base have also been used in USA. Recently a nonoil-based $100 \mathrm{mg}$ progesterone tablet became available (Endometrin; Ferring Pharmaceuticals) for vaginal use. No pessary is available in the USA, but $200 \mathrm{mg}$ and $400 \mathrm{mg}$ progesterone pessary wrapped in wax is available in Europe (Cyclogest; Actavis UK, Devon, UK). All the above products are currently available and approved for other indications, but not for prevention of preterm labor.

Progesterone derives its name from 'progestational steroid hormone' due to its primary function of preparing and 


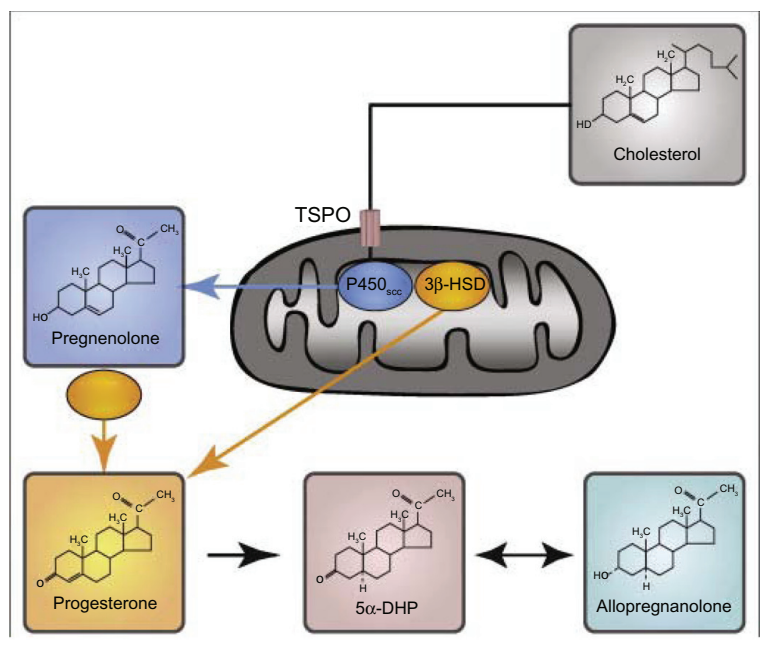

METABOLISM

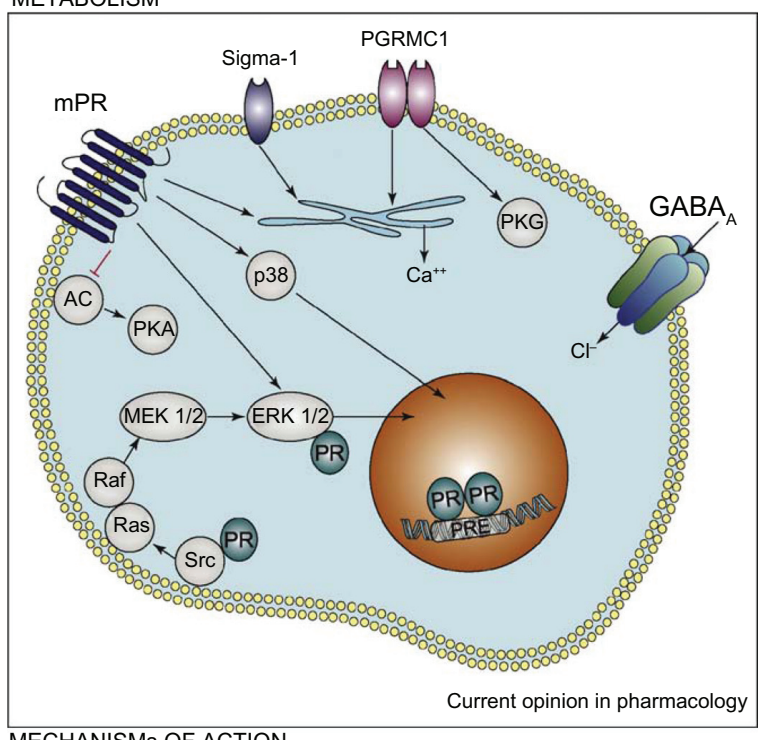

MECHANISMs OF ACTION

Figure I Cholesterol is converted to pregnenolone by cytochrome $\mathrm{P}^{4} \mathrm{~S}_{\text {scc }}$ inside steroidogenic mitochondria. The transport of cholesterol across the mitochondrial membranes is a limiting step, and it involves the transport protein (TSPO). Ligands of TSPO can stimulate the passage of cholesterol into the mitochondria and, as a consequence, the synthesis of pregnenolone. The conversion of pregnenolone to progesterone by different isoforms of the $3 \beta$-hydroxysteroid dehydrogenase $(3 \beta-\mathrm{HSD})$ also takes place inside the mitochondria or within the cytoplasm.

Notes: Progesterone regulates gene transcription by binding to intracellular receptors (PR), which interact as dimers with DNA progesterone-response elements (PREs). In addition, PR can also directly interact with extranuclear signaling proteins of the Src/Ras/Erk pathway. At the level of the plasma membrane, progesterone binds to the recently identified membrane receptors of progesterone (mPR, comprising $\mathrm{a}, \mathrm{b}$, and $\mathrm{g}$ isoforms), progesterone receptor membrane component I (PGRMCI, the former protein 25Dx) and the $s$ l receptor. Major signal transduction pathways which have been shown to be activated by the mPRs are ERK and $p 38$. The $\mathrm{mPRs}$ also inhibit adenylate cyclase (AC), and as a consequence the protein kinase A (PKA) pathway, and they stimulate $\mathrm{Ca}^{2+}$ release from internal stores. Likewise, PGRMCI and sI receptors increase intracellular $\mathrm{Ca}^{2+}$ release. Both receptors are also located on membranes inside the cytoplasm, but they may translocate from them to the plasma membrane. In addition, PGRMCI has been shown to activate protein kinase $\mathrm{G}$ (PKG), and $\mathrm{s}$ I receptors function as amplifiers of ion channels (eg, voltage-gated $\mathrm{K}+$ channels). Progesterone also activates $\gamma$-aminobutyric acid type $\mathrm{A}$ $\left(\mathrm{GABA}_{\mathrm{A}}\right)$ receptors via its metabolite allopregnanolone.

Copyright (C) 2008, Elsevier. Reproduced with permission from Schumacher M, Sitruk-Ware R, De Nicola AF. Progesterone and progestins: neuroprotection and myelin repair. Curr Opin Pharmacol. 2008;8:740-746.32

Abbreviation: $5 \alpha \mathrm{DHP}, 5 \alpha$ dihydroprogesterone. maintaining the uterine bed for conception. ${ }^{38}$ Its benefits in decreasing early pregnancy loss via providing luteal support, both in women with threatened abortion and those undergoing artificial reproduction cycles, has led to its widespread use in the first trimester. ${ }^{39,40}$ Its role in the 2 nd and 3rd trimesters of pregnancy is less clear, but its effects on the uterus (myometrium and cervix) form a biological plausible reason for its role in prevention of sPTB. Progesterone inhibits production of stimulatory prostaglandins ( $\mathrm{PG}$ ) and expression of contraction-associated protein genes in the myometrium. ${ }^{38}$ Clinically, this correlates with its mild tocolytic effects and significantly decreased spontaneous uterine contractions in women receiving progesterone compared to control groups. ${ }^{41}$ However, this has not translated into a clinical success as a stand-alone tocolytic, but progesterone possibly could have adjunctive role in decreasing SPTB in women with threatened or established preterm labor. ${ }^{42}$

In contrast to traditional concepts, progesterone's most significant actions appear to be on the cervix and thus in prevention rather than treatment of $\mathrm{SPTB} .{ }^{43,44}$ As the 'gatekeeper for pregnancy', ${ }^{45}$ the cervix remains firm, long and closed to contain and protect the conceptus from outside influences for the duration of the pregnancy. It remodels (softens, ripens, and dilates) to herald the onset of parturition which begins several days or weeks prior to onset of regular uterine contractions, a late step in the parturition process. ${ }^{44}$ Cervical remodeling occurs with loss of tissue effects of progesterone. This is supported by the fact that administration of antiprogestins like RU-486 (mifepristone) in mid-trimester or term, results in cervical ripening not labor. ${ }^{44,46}$ The prolonged interval between cervical ripening and labor, allows for the opportunity to institute measures to arrest further progression of the process and prolong gestation.

Multiple mechanisms have been proposed to explain the role of progesterone in uterine quiescence and its deficiency (relative or absolute) resulting in parturition. ${ }^{38}$ In many animal species, systemic drop in progesterone levels heralds the onset of parturition. However, in humans, systemic progesterone levels remain high until after delivery of the placenta. Current evidence suggests that decrease in local progesterone responsiveness, termed 'functional withdrawal' heralds cervical remodeling. Progesterone effects gene transcription via activation of the progesterone receptor (PR) isoforms A and B. Progesterone-responsive genes are suppressed by PR-A, but activated by PR-B (Figure 1). The ratio of $\mathrm{PR}-\mathrm{A} / \mathrm{PR}-\mathrm{B}$ determines progesterone action with an increase in PR-A expression initiating cervical ripening. Another mechanism proposed for the 'functional' 
progesterone withdrawal is a decrease in PR coactivators, resulting in impaired progesterone-PR interaction, and thus reduced expression of progesterone-responsive genes. The differential expression of the PR is hypothesized to be mediated by PGs, inflammatory cytokines, and/or estrogen activation. Progesterone also exerts anti-inflammatory actions by inhibiting the transcription factor, nuclear factor- $\kappa \mathrm{B}$, which results in decreased cyclooxygenase- 2 and PG synthase actions, and low PG levels. A second pathway to suppress PG production within the endometrium/ decidua is to upregulate production of the unbound secretory component of immunoglobulin A (IgA) which directly inhibits phospholipase $\mathrm{A}_{2}$ and thus suppresses endometrial PG synthesis and release. In addition to the gene effects, progesterone can act via membrane-bound receptors and nongenomic pathways to suppress cytokine mediated inflammatory response. Progesterone decreases myometrial responsiveness by inhibiting estrogen receptor- $\alpha$ expression, and its byproducts competitively bind to oxytocin receptors and decrease oxytocin-induced contractility. Another hypothesis proposed for timing of labor is the maturation of the fetal hypothalamic-pituitary-adrenal axis resulting in cortisol secretion which regulates placental corticotrophinreleasing hormone (pCRH). ${ }^{47} \mathrm{CRH}$ stimulates decidual PG secretion and increases myometrial responsiveness. Progesterone and cortisol have opposing actions in the fetoplacental unit and compete for regulation of $\mathrm{pCRH}$ gene expression. Exogenous progesterone supplementation may effectively restore some, but not all, of its actions to maintain uterine quiescence. This may explain why SPTB is prevented in some women using progesterone, but not universally. In others, the process of parturition may have progressed beyond the point of no return.

\section{Efficacy studies}

After the initial success of synthetic progesterone in prevention of recurrent sPTB in women with prior $\mathrm{SPTB},{ }^{48}$ investigation into the use of more convenient vaginal progesterone in this high risk population was met with controversial findings. . $^{41,49}$ Looking at benefits of vaginal progesterone in other risk factors for SPTB only further heightened this controversy. The Turkish study in 150 high-risk women (with twins, uterine malformation or prior sPTB) showed lower sPTB and neonatal intensive care unit (NICU) admissions with use of $100 \mathrm{mg}$ vaginal progesterone suppository, ${ }^{50}$ but the Danish study in 675 twin pregnancies showed no benefit from $200 \mathrm{mg}$ vaginal suppository. ${ }^{51}$ However, controversial findings of these different studies suggested and helped identify a subgroup of particularly at-risk women for SPTB in which vaginal progesterone could be beneficial. The secondary analysis of the vaginal gel study in women with prior SPTB showed that using objective criteria such as ultrasonographically detected $\mathrm{SCL}$, a stronger predictor of sPTB, ${ }^{10,52}$ was better able to identify women who could benefit from prophylactic treatment with vaginal progesterone. ${ }^{27}$ The investigators showed that daily use of $90 \mathrm{mg}$ vaginal progesterone gel not only decreased risk of early sPTB $\leq$ 32 weeks in women with $\mathrm{CL}<28 \mathrm{~mm}$ identified between 18.0 and 22.9 weeks of gestation, but also improved neonatal outcomes, the ultimate goal of therapy. The SPTB rate with vaginal gel progesterone compared to placebo (Replens ${ }^{\mathbb{B}}$; Columbia Laboratories, Inc, Livingston, NJ) was 0 vs $29.6 \%$; $P=0.01$; lower NICU admissions ( 15.8 vs $51.9 \%, P=0.01$ ); shorter NICU stay ( 1.1 vs 16.5 days; $P=0.01$ ), and a trend towards lower occurrence of respiratory distress syndrome (RDS) $(5.3 \%$ vs $29.6 \% ; P=0.06) .{ }^{27}$ At the same time, the Fetal Medicine Foundation second trimester screening group from London, UK had reported $44 \%$ lower sPTB $<34$ weeks with once-daily $200 \mathrm{mg}$ progesterone suppositories $(19.2 \%$ vs $34.4 \% ; P=0.007)$ in women with $20-25$ week CL $\leq 15 \mathrm{~mm} \cdot{ }^{28}$ However, they noted a nonsignificant reduction in composite adverse neonatal outcomes $(8.1 \%$ vs $13.8 \%$; $P=0.17)$. Subsequently the largest-to-date prospective, randomized, placebo-controlled, double-blind, parallelgroup study was conducted at 44 centers in 10 countries using progesterone vaginal gel in women with $19-<24$ week CL of $10-20 \mathrm{~mm} .{ }^{29}$ In the 458 women enrolled, the gel decreased sPTB $<33$ weeks by $45 \%$ in comparison to placebo users ( $8.9 \%$ vs $16.1 \% ; P=0.02)$. There was also a $38 \%$ reduction in $\mathrm{sPTB}<35(14.5 \%$ vs $23.3 \% ; P=0.02)$ and a $50 \%$ reduction $<28$ weeks $(5.1 \%$ vs $10.3 \% ; P=0.04)$. Improvement in neonatal outcome was also demonstrated with lower incidence of RDS ( $3 \%$ vs $7.6 \% ; P=0.03$ ); lower rate of any morbidity or mortality $(7.7 \%$ vs $13.5 \%, P=0.04)$; and reduction in neonates with birth weight $<1500 \mathrm{~g}$ (6.4\% vs $13.6 \% ; P=0.01)$. Romero and colleagues then conducted an individual patient data meta-analysis of randomized controlled trials in asymptomatic women with midtrimester $\mathrm{CL} \leq 25 \mathrm{~mm}$, as the resultant larger sample size would provide greater statistical power for subgroup analyses, improve standardization and consistency across data sets, and allow time-to-event analyses. ${ }^{30}$ Analysis of 775 women (723 singleton and 52 twin pregnancies) confirmed reduction in risk of sPTB $<33$ weeks in both women with singleton gestation without prior $\mathrm{PPTB}$ (relative risk $[R R]=0.60 ; 95 \%$ confidence interval $[\mathrm{CI}]: 0.39-0.92$ ) 
as well as women with $\geq 1$ prior $\mathrm{sPTB}$ ( $\mathrm{RR}=0.54$; $95 \%$ CI: $0.30-0.98$ ) with improved composite neonatal outcomes in both groups. In singletons, neonatal outcomes significantly improved were $\mathrm{RDS}$ ( $\mathrm{RR}=0.47$; 95\% CI: $0.27-0.81$ ); composite neonatal morbidity and mortality $(\mathrm{RR}=0.59 ; 95 \%$ CI: 0.38-0.91); apgar score $<7$ at 5 minutes $(\mathrm{RR}=0.48$; 95\% CI: 0.24-0.95); NICU admissions ( $R R=0.67 ; 95 \%$ CI: $0.50-0.91)$; and birth weight $<1500 \mathrm{~g}(\mathrm{RR}=0.52 ; 95 \%$ CI: $0.34-0.81$ ). The meta-analysis recommended a future, properly designed study in twin pregnancies with short cervix as the analysis showed nonsignificant reductions in early sPTB $<33$ weeks ( $\mathrm{RR}=0.70$; 95\% CI: 0.34-1.44); and $<28$ weeks $(\mathrm{RR}=0.44,95 \% \mathrm{CI}: 0.11-1.85)$ but significant reduction in composite neonatal morbidity and mortality ( $\mathrm{RR}=0.52 ; 95 \% \mathrm{CI}: 0.29-0.93)$.

\section{Comparative studies}

Currently, there are no studies comparing any of the formulations of progesterone to each other for prevention of sPTB. However, for luteal phase support in women undergoing assisted reproductive technologies, vaginal progesterone (oil-in-capsule or the gel) was comparable to the IM form on the clinical end-points (clinical pregnancy and ongoing pregnancies). ${ }^{53,54}$ Pharmacokinetic comparisons have shown higher endometrial tissue levels despite lower serum levels with vaginal $(1.05 \pm 0.67 \mathrm{ng} / \mathrm{mg}$ protein and $4.82 \pm 2.25 \mathrm{ng} / \mathrm{mL}$, respectively $)$ compared to IM $(0.43 \pm 0.19 \mathrm{ng} / \mathrm{mg}$ protein and $29.42 \pm 14.14 \mathrm{ng} / \mathrm{mL}$, respectively) preparations. ${ }^{36,55}$

\section{Vaginal gel progesterone Safety and tolerability}

The synthetic progesterones administered parenterally result in undesirable side effects like alteration in lipid levels, glucose metabolism, a hypercoagulant state, vasomotility, edema, central nervous system effects like sedation, fatigue, dizziness and dysphoria, gastrointestinal effects like abdominal cramps, back pain, nausea, and constipation; reproductive system effects like vaginal bleeding and breast tenderness. ${ }^{33}$ These side effects are decreased with the micronized form and systemic effects almost eliminated with the vaginal form. The most common side effects reported with the vaginal form include vaginal discharge, vaginal pruritus, drowsiness, nausea, and 'feeling of coolness' in the vagina. ${ }^{29,54,57}$

The gel formulation contains $90 \mathrm{mg}$ micronized progesterone mixed in a small volume of nonimmunogenic polycarbophil gel, which is an oil-in-water emulsion. The polycarbophil base attaches to the vaginal epithelial cells until they turn over every $3-5$ days. The progesterone is partially soluble in both oil and water phases, with the aqueous form being absorbed by facilitated diffusion across the vaginal wall. The progesterone stored in the oil reservoir replaces the depleted aqueous form, resulting in controlled release of the drug. So the gel form does not result in leakage, unlike the suppositories which can be messy as the oil base liquefies at body temperature. The resulting leakage causes vaginal irritation and yeast infections at ten times greater frequency with suppositories compared to the gel formulation. ${ }^{54,56}$ However, the gel can result in vaginal build-up, cloddy discharge, and vaginal irritation in up to $2 \%-4 \%$ of patients in the 2 nd and 3 rd trimesters ${ }^{29,49}$ and $7 \%$ in the 1 st trimester. ${ }^{57}$ The increased incidence in the 1 st trimester is most likely due to more frequent administration. These side effects are due to the vehicle rather than the drug itself.

Safety of progesterone is well established in the 1 st trimester and exemplified by its popular use for luteal phase support in both natural and assisted pregnancies. ${ }^{54,58,59}$ Safety in the 2nd and 3rd trimesters has only recently been established in prospectively randomized, double-blind, placebo-controlled trials..$^{28,29,41,49-51}$ In a meta-analysis, no difference was noted between progesterone and placebo groups with respect to congenital anomalies (1.5 vs $1.7 \%$; $95 \% \mathrm{CI}$ : $0.55-1.44)$; any maternal adverse event (13.8 vs $13.4 \%$; 95\% CI: $0.79-1.38$ ); vaginal discharge ( 22.9 vs $23.5 \%$; $95 \%$ CI: $0.87-1.15$ ); and vaginal pruritus ( 5.1 vs $4.7 \%$; $95 \% \mathrm{CI}$ : $0.74-1.57) .{ }^{30}$ Rate of therapy discontinuation due to gel side effects was $1.6 \%$ in one study (one patient stopped due to vaginal discharge and other two due to nausea $)^{49}$ and overall with all vaginal formulations was $2.6 \%$ in both drug and placebo groups. ${ }^{30}$ Follow-up of neonates was reported in two trials, one using the suppository and the other using the gel. ${ }^{51,60}$ Rode and colleagues reported neurodevelopmental disability using the Ages and Stages Questionnaire (ASQ) scores in neonates exposed to progesterone suppositories in the PREDICT trial at $6(79.2 \%)$ and 18 months (74.8\%). The mean ASQ scores $(193 \pm 42.6$ vs $194 \pm 40.6 ; P=0.89)$ or the proportions below 115 at 18 months were similar (3.8\% vs $3.7 \%$ ) in the progesterone and placebo groups, respectively. ${ }^{51}$ Infants exposed to the vaginal gel trial were evaluated at 6 (69.9\%), 12 (61.1\%), and 24 months (46\%) for biometric growth, developmental debilities by Denver II screening test (10.3\% vs $10.4 \%$; $95 \%$ CI: $0.62-1.55$ ), chronic morbid conditions (5.6\% vs 5.4\%; 95\% CI: $0.55-1.99)$ and congenital abnormalities (3.4\% vs 3.8\%; 95\% CI: 0.4-2.01). Again, no differences were noted between progesterone and placebo groups in neonatal parameters up to 24 months. ${ }^{60}$ 


\section{Patient-focused perspectives patient satisfaction/acceptability, adherence}

Overall vaginal progesterone is safe for the mother and fetus with minimal side-effects when compared to placebo. The adverse effects are similar with all vaginal forms of progesterone. ${ }^{54}$ Comparing vaginal gel to oil-in-capsules, patients find the gel more convenient and easy to use as there is less vaginal discharge and fewer application difficulties. ${ }^{61,62}$ Despite equivalent efficacy of different forms of natural progesterone, the gel provides superior acceptability and tolerability due to less leakage and once daily application with a tampon-like familiar insertion. ${ }^{61}$ In the reported trials, over $98 \%$ patients accepted a complete course of vaginal gel therapy with high compliance rates of 93\%-96\%. ${ }^{29,49}$ Women express greater satisfaction with the convenience of administration of vaginal gel progesterone compared to the discomfort with IM progesterone. ${ }^{63}$

\section{Conclusion: place in therapy}

In summary, there is ample Level 1 evidence supporting use of vaginal progesterone in women with midtrimester short cervix to decrease sPTB. Adding to this benefit is the fact that it has no significant adverse effects for mother or the neonate. Critics argue that with low frequency of sCL (Table 3), low sensitivity of SCL to predict preterm delivery, and only $\sim 40 \%$ reduction of sPTB will result in many women undergoing the treatment unnecessarily. However, proponents would argue that the data suggests that only 11 need to be treated to prevent one sPTB. ${ }^{41}$ This one prevented SPTB will result in insurmountable benefits not only to that neonate, but also to that family, and the society not only monetarily but also emotionally and intellectually and lighten the burden of chronic diseases. Even if critics argue regarding the degree of benefit, the risk-benefit ratio balance tips towards vaginal progesterone use in women with sCL especially as there are no significant side effects. Therefore I recommend universal CL screening of all women with singleton gestation at midtrimester, and offering prophylactic treatment with vaginal progesterone in those with sCL. I believe this will become the standard of care.

\section{Disclosure}

The author was an investigator in the 'PREGNANT' trial, and was also a paid consultant as part of the Watson Pharmaceutical Team presenting to FDA in 2011 for vaginal progesterone gel.

\section{References}

1. Hamilton BE, Martin JA, Ventura SJ. Births: preliminary data for 2010. Natl Vital Stat Rep. 2011;60:1-26.
2. Mathews TJ, MacDorman MF. Infant mortality statistics from the 2008 period linked birth/infant death data set. Natl Vital Stat Rep. 2012;60: $1-49$.

3. Saigal S, Doyle LW. An overview of mortality and sequelae of preterm birth from infancy to adulthood. Lancet. 2008;371:261-269.

4. McCormick MC, Litt JS, Smith VC, Zupancic JAF. Prematurity: an overview and public health implications. Ann Rev Public Health. 2011; 32:367-379.

5. Russell RB, Green NS, Steiner CA, et al. Cost of hospitalization for preterm and low birth weight infants in the United States. Pediatrics. 2007;120:e1-e9.

6. National Research Council. Preterm birth: causes, consequences, and prevention. In: Behrman RE, Butler AS, editors. Committee on Understanding Premature Birth Assuring Healthy Outcomes. Washington, DC: The National Academies Press; 2007.

7. March of Dimes Foundation. Medical costs for one premature baby could cover a dozen healthy births. March 17, 2009. Available from: http://www.eurekalert.org/pub_releases/2009-03/modf-mcf031309. php. Accessed on August 1, 2012.

8. Heath VC, Southall TR, Souka AP, Elisseou A, Nicolaides KH. Cervical length at 23 weeks of gestation: prediction of spontaneous preterm delivery. Ultrasound Obstet Gynecol. 1998;12:312-317.

9. Andersen HF, Nugent CE, Wanty SD, Hayashi RH. Prediction of risk for preterm delivery by ultrasonographic measurement of cervical length. Am J Obstet Gynecol. 1990;163:859-867.

10. Iams JD, Goldenberg RL, Meis PJ, et al. The length of the cervix and the risk of spontaneous premature delivery. National Institute of Child Health and Human Development Maternal Fetal Medicine Unit Network. N Engl J Med. 1996;334:567-572.

11. Taipale P, Hiilesmaa V. Sonographic measurement of uterine cervix at 18-22 weeks' gestation and the risk of preterm delivery. Obstet Gynecol. 1998;92:902-907.

12. Ross MG, Cousins L, Baxter-Jones R, Bemis-Heys R, Catanzarite V, Dowling D. Objective cervical portio length measurements: consistency and efficacy of screening for a short cervix. J Reprod Med. 2007;52: 385-389.

13. Andersen HF. Transvaginal and transabdominal ultrasonography of the uterine cervix during pregnancy. J Clin Ultrasound. 1991;19:77-83.

14. Okitsu O, Mimura T, Nakayama T, Aono T. Early prediction of preterm delivery by transvaginal ultrasonography. Ultrasound Obstet Gynecol. 1992;2:402-409.

15. Heath VC, Southall TR, Souka AP, Novakov A, Nicolaides KH. Cervical length at 23 weeks of gestation: relation to demographic characteristics and previous obstetric history. Ultrasound Obstet Gynecol. 1998;12:304-311.

16. Clement S, Candy B, Heath V, To M, Nicolaides KH. Transvaginal ultrasound in pregnancy: its acceptability to women and maternal psychological morbidity. Ultrasound Obstet Gynecol. 2003;22: 508-514.

17. Olatunbosun OA, al-Nuaim L, Turnell RW. Emergency cerclage compared with bed rest for advanced cervical dilatation in pregnancy. Int Surg. 1995;80:170-174.

18. Arisoy R, Yayla M. Transvaginal sonographic evaluation of the cervix in asymptomatic singleton pregnancy and management options in short cervix. J Pregnancy. 2012;201628:22.

19. Lockwood C. The real progesterone story: Exploring the Makena drug controversy. Contemp Ob/Gyn. 2011;56:10-14.

20. Campbell S. Universal cervical-length screening and vaginal progesterone prevents early preterm births, reduces neonatal morbidity and is cost saving: doing nothing is no longer an option. Ultrasound Obstet Gynecol. 2011;38:1-9.

21. Combs CA. Vaginal progesterone for asymptomatic cervical shortening and the case for universal screening of cervical length. Am J Obstet Gynecol. 2012;206:101-103.

22. Society for Maternal-Fetal Medicine Publications Committee. Progesterone and preterm birth prevention: translating clinical trials data into clinical practice. Am J Obstet Gynecol. 2012;206:376-386. 
23. Cahill AG, Odibo AO, Caughey AB, et al. Universal cervical length screening and treatment with vaginal progesterone to prevent preterm birth: a decision and economic analysis. Am J Obstet Gynecol. 2010; 202:548. e1-e8.

24. Werner EF, Han CS, Pettker CM, et al. Universal cervical-length screening to prevent preterm birth: a cost-effectiveness analysis. Ultrasound Obstet Gynecol. 2011;38:32-37.

25. Iams JD, Johnson FF, Sonek J, Sachs L, Gebauer C, Samuels P. Cervical competence as a continuum: a study of ultrasonographic cervical length and obstetric performance. Am J Obstet Gynecol. 1995;172:1097-1103; discussion, 104-106.

26. Berghella V, Roman A, Daskalakis C, Ness A, Baxter JK. Gestational age at cervical length measurement and incidence of preterm birth. Obstet Gynecol. 2007;110:311-317.

27. DeFranco EA, O'Brien JM, Adair CD, et al. Vaginal progesterone is associated with a decrease in risk for early preterm birth and improved neonatal outcome in women with a short cervix: a secondary analysis from a randomized, double-blind, placebo-controlled trial. Ultrasound Obstet Gynecol. 2007;30:697-705.

28. da Fonseca EB, Celik E, Parra M, Singh M, Nicolaides KH. Progesterone and the risk of preterm birth among women with a short cervix. $N$ Engl J Med. 2007;357:462-469.

29. Hassan SS, Romero R, Vidyadhari D, et al. Vaginal progesterone reduces the rate of preterm birth in women with a sonographic short cervix: a multicenter, randomized, double-blind, placebo-controlled trial. Ultrasound Obstet Gynecol. 2011;38:18-31.

30. Romero R, Nicolaides K, Conde-Agudelo A, et al. Vaginal progesterone in women with an asymptomatic sonographic short cervix in the midtrimester decreases preterm delivery and neonatal morbidity: a systematic review and metaanalysis of individual patient data. $\mathrm{Am} \mathrm{J}$ Obstet Gynecol. 2012;206:124. e1-e19.

31. Owen J, Hankins G, Iams JD, et al. Multicenter randomized trial of cerclage for preterm birth prevention in high-risk women with shortened midtrimester cervical length. Am J Obstet Gynecol. 2009;201 375. e1-e8.

32. Schumacher M, Sitruk-Ware R, De Nicola AF. Progesterone and progestins: neuroprotection and myelin repair. Curr Opin Pharmacol. 2008;8:740-746.

33. Goletiani NV, Keith DR, Gorsky SJ. Progesterone: Review of safety for clinical studies. Exper Clin Psychopharmacol. 2007;15:427-444.

34. Xu H, Gonzalez JM, Ofori E, Elovitz MA. Preventing cervical ripening: the primary mechanism by which progestational agents prevent preterm birth? Am J Obstet Gynecol. 2008;198:314. e1-314. e8.

35. de Lignieres B. Oral micronized progesterone. Clin Ther. 1999;21:41-60; discussion 1-2.

36. Cicinelli E, de Ziegler D, Bulletti C, Matteo MG, Schonauer LM, Galantino P. Direct transport of progesterone from vagina to uterus. Obstet Gynecol. 2000;95:403-406.

37. Fanchin RM, De Ziegler DM, Bergeron CP, Righini CM, Torrisi CM, Frydman RM. Transvaginal administration of progesterone. Obstet Gynecol. 1997;90:396-401.

38. Sfakianaki AK, Norwitz ER. Mechanisms of progesterone action in inhibiting prematurity. J Matern Fetal Neonatal Med. 2006;19. 763-772.

39. Daya S. Luteal support: progestogens for pregnancy protection. Maturitas. 2009;65 Suppl 1:S29-S34.

40. Wahabi HA, Abed Althagafi NF, Elawad M, Al Zeidan RA. Progestogen for treating threatened miscarriage. Cochrane Database Syst Rev. 2011 12:CD005943.

41. da Fonseca EB, Bittar RE, Carvalho MH, et al. Prophylactic administration of progesterone by vaginal suppository to reduce the incidence of spontaneous preterm birth in women at increased risk: a randomized placebo-controlled double-blind study. [see comment.] Am J Obstet Gynecol. 2003;188:419-424.

42. Su L-L, Samuel M, Chong Y-S. Progestational agents for treating threatened or established preterm labour. Cochrane Database Syst Rev. 2010;1:CD006770.
43. Romero R. Prevention of spontaneous preterm birth: the role of sonographic cervical length in identifying patients who may benefit from progesterone treatment. Ultrasound Obstet Gynecol. 2007;30: 675-686.

44. Word RA, Li X-H, Hnat M, Carrick K. Dynamics of cervical remodeling during pregnancy and parturition: mechanisms and current concepts. Semin Reprod Med. 2007;25:69-79.

45. Yellon SM, Burns AE, See JL, Lechuga TJ, Kirby MA. Progesterone withdrawal promotes remodeling processes in the nonpregnant mouse cervix. Biol Reprod. 2009;81:1-6.

46. Chwalisz $\mathrm{K}$. The use of progesterone antagonists for cervical ripening and as an adjunct to labour and delivery. Hum Reprod. 1994;9 Suppl 1: 131-161.

47. Jeschke U, Mylonas I, Richter D-U, et al. Regulation of progesterone production in human term trophoblasts in vitro by $\mathrm{CRH}, \mathrm{ACTH}$ and cortisol (prednisolone). Arch Gynecol Obstet. 2005;272:7-12.

48. Meis PJ, Klebanoff M, Thom E, et al. Prevention of recurrent preterm delivery by 17 alpha-hydroxyprogesterone caproate. $N$ Engl $J$ Med. 2003;348:2379-2385.

49. O'Brien JM, Adair CD, Lewis DF, et al. Progesterone vaginal gel for the reduction of recurrent preterm birth: primary results from a randomized, double-blind, placebo-controlled trial. Ultrasound Obstet Gynecol. 2007;30:687-696.

50. Cetingoz E, Cam C, Sakalli M, Karateke A, Celik C, Sancak A. Progesterone effects on preterm birth in high-risk pregnancies: a randomized placebo-controlled trial. Arch Gynecol Obstet. 2011;283: 423-429.

51. Rode L, Klein K, Nicolaides KH, Krampl-Bettelheim E, Tabor A; for the PREDICT Group. Prevention of preterm delivery in twin gestations (PREDICT): a multicenter, randomized, placebo-controlled trial on the effect of vaginal micronized progesterone. Ultrasound Obstet Gynecol. 2011;38:272-280.

52. To MS, Skentou CA, Royston P, Yu CKH, Nicolaides KH. Prediction of patient-specific risk of early preterm delivery using maternal history and sonographic measurement of cervical length: a population-based prospective study. Ultrasound Obstet Gynecol. 2006;27:362-367.

53. Zarutskie PW, Phillips JA. A meta-analysis of the route of administration of luteal phase support in assisted reproductive technology: vaginal versus intramuscular progesterone. Fertil Steril. 2009;92:163-169.

54. Polyzos NP, Messini CI, Papanikolaou EG, et al. Vaginal progesterone gel for luteal phase support in IVF/ICSI cycles: a meta-analysis. Fertil Steril. 2010;94:2083-2087.

55. Miles RA, Paulson RJ, Lobo RA, Press MF, Dahmoush L, Sauer MV. Pharmacokinetics and endometrial tissue levels of progesterone after administration by intramuscular and vaginal routes: a comparative study. Fertil Steril. 1994;62:485-490.

56. Germond M, Capelli P, Bruno G, et al. Comparison of the efficacy and safety of two formulations of micronized progesterone (Ellios and Utrogestan) used as luteal phase support after in vitro fertilization. Fertil Steril. 2002;77:313-317.

57. Kleinstein J, Luteal Phase Study G. Efficacy and tolerability of vaginal progesterone capsules (Utrogest 200) compared with progesterone gel (Crinone 8\%) for luteal phase support during assisted reproduction. Fertil Steril. 2005;83:1641-1649.

58. Haas DM, Ramsey PS. Progestogen for preventing miscarriage. Cochrane Database Sys Rev. 2008:CD003511.

59. Katz Z, Lancet M, Skornik J, Chemke J, Mogilner BM, Klinberg M. Teratogenicity of progestogens given during the first trimester of pregnancy. Obstet Gynecol. 1985;65:775-780.

60. O'Brien JM, Steichen JJ, Phillips JA, Creasy GW. 490: Two year infant outcomes for children exposed to supplemental intravaginal progesterone gel in utero: secondary analysis of a multicenter, randomized, double-blind, placebo-controlled trial. Am J Obstet Gynecol. 2012;206:S223.

61. Simunic V, Tomic V, Tomic J, Nizic D. Comparative study of the efficacy and tolerability of two vaginal progesterone formulations, Crinone $8 \%$ gel and Utrogestan capsules, used for luteal support. Fertil Steril. 2007;87:83-87. 
62. Ludwig M, Schwartz P, Babahan B, et al. Luteal phase support using either Crinone $8 \%$ or Utrogest: results of a prospective, randomized study. Eur J Obstet Gynecol Reprod Biol. 2002;103:48-52.

63. Yanushpolsky E, Hurwitz S, Greenberg L, Racowsky C, Hornstein M. Crinone vaginal gel is equally effective and better tolerated than intramuscular progesterone for luteal phase support in in vitro fertilizationembryo transfer cycles: a prospective randomized study. Fertil Steril. 2010;94:2596-2599.

64. Shamansky SL, Clausen CL. Levels of prevention: examination of the concept. Nurs Outlook. 1980;28:104-108.

65. Ramaeker DM, Simhan HN. Sonographic cervical length, vaginal bleeding, and the risk of preterm birth. Am J Obstet Gynecol. 2012; 206:224. e1-e4.

66. Mercer BM, Goldenberg RL, Das A, et al. The preterm prediction study: a clinical risk assessment system. Am J Obstet Gynecol. 1996;174:1885-1893; discussion, 93-95.

67. Honest H, Bachmann LM, Sundaram R, Gupta JK, Kleijnen J, Khan KS. The accuracy of risk scores in predicting preterm birth - a systematic review. J Obstet Gynaecol. 2004;24:343-359.

68. Leitich H, Egarter C, Kaider A, Hohlagschwandtner M, Berghammer P, Husslein P. Cervicovaginal fetal fibronectin as a marker for preterm delivery: a meta-analysis. Am J Obstet Gynecol. 1999;180: 1169-1176.

69. Yang J, Hartmann KE, Savitz DA, et al. Vaginal bleeding during pregnancy and preterm birth. Am J Epidemiol. 2004;160:118-125.

70. Goldenberg RL, Culhane JF, Iams JD, Romero R. Epidemiology and causes of preterm birth. Lancet. 2008;371:75-84.

71. Mandal D, Manda S, Rakshi A, Dey RP, Biswas SC, Banerjee A. Maternal obesity and pregnancy outcome: a prospective analysis. JAssoc Physicians India. 2011;59:486-489.
72. Smith GCS, Pell JP, Dobbie R. Interpregnancy interval and risk of preterm birth and neonatal death: retrospective cohort study. [Erratum appears in BMJ. 2003;327(7419):851.] BMJ. 2003;327:313.

73. Ofori BD, Le Tiec M, Berard A. Risk factors associated with preterm birth according to gestational age at birth. Pharmacoepidemiol Drug Saf. 2008;17:556-564.

74. Hua M, Odibo AO, Longman RE, Macones GA, Roehl KA, Cahill AG. Congenital uterine anomalies and adverse pregnancy outcomes. Am J Obstet Gynecol. 2011;205:22.

75. Vergnes J-N, Sixou M. Preterm low birth weight and maternal periodontal status: a meta-analysis. Am J Obstet Gynecol. 2007;196: 135.e1-135.e7.

76. Hassan SS, Romero R, Berry SM, et al. Patients with an ultrasonographic cervical length $<$ or $=15 \mathrm{~mm}$ have nearly a $50 \%$ risk of early spontaneous preterm delivery. Am J Obstet Gynecol. 2000;182:1458-1467.

77. Moroz LA, Simhan HN. Rate of sonographic cervical shortening and the risk of spontaneous preterm birth. Am J Obstet Gynecol. 2012;206: 234. e1-e5.

78. Grobman WA; for the Eunice Kennedy Shriver National Institute of Health and Human Development. Randomized controlled trial of progesterone treatment for preterm birth prevention in nulliparous women with cervical length less than $30 \mathrm{~mm}$. Am J Obstet Gynecol. 2012;206:S367.

79. Mercer BM, Goldenberg RL, Moawad AH, et al. The preterm prediction study: effect of gestational age and cause of preterm birth on subsequent obstetric outcome. NICHHD MFMU Network. Am J Obstet Gynecol. 1999;181:1216-1221.
International Journal of Women's Health

\section{Publish your work in this journal}

The International Journal of Women's Health is an international, peerreviewed open-access journal publishing original research, reports, reviews and commentaries on all aspects of women's healthcare including gynecology, obstetrics, and breast cancer. Subject areas include: Chronic conditions (migraine headaches, arthritis, osteoporosis);

\section{Dovepress}

Endocrine and autoimmune syndromes; Sexual and reproductive health; Psychological and psychosocial conditions. The manuscript management system is completely online and includes a very quick and fair peer-review system. Visit http://www.dovepress.com/ testimonials.php to read real quotes from published authors. 